Original Article

\title{
Eltgol Acutelly Improves Airway Clearance and Reduces Static Pulmonary Volumes in Adult Cystic Fibrosis Patients
}

\author{
Fernando Silva Guimarães ${ }^{1,2)^{*}}$, Agnaldo José Lopes ${ }^{1,3)}$, Vanessa Joaquim Ribeiro Moço ${ }^{1)}$, \\ Felipe Cavalcanti de Souza ${ }^{1)}$, Sara Lúcia Silveira de Menezes ${ }^{1,2)}$ \\ 1) Rehabilitation Science Graduate Program, Augusto Motta University Centre (UNISUAM): \\ Praça das Nações, 34, Bonsucesso, Rio de Janeiro 21041-021, Brazil \\ 2) Physical Therapy Department, Federal University of Rio de Janeiro, Brazil \\ 3) Laboratory of Respiratory Physiology, University of the State of Rio de Janeiro, Brazil
}

\begin{abstract}
Purpose] Chest physical therapy techniques are essential in order to reduce the frequency of recurrent pulmonary infections that progressively affect lung function in cystic fibrosis patients. Recently, ELTGOL (L'Expiration Lente Totale Glotte Ouverte en décubitus Latéral) emerged as an inexpensive and easy to perform therapeutic option. The aim of this study was to compare the acute effects of ELTGOL and the Flutter valve in stable adult patients with cystic fibrosis. [Subjects and Methods] This was a randomized, crossover study with a sample of cystic fibrosis outpatients. The subjects underwent two protocols (Flutter Valve and ELTGOL interventions, referred to as ELTGOL and FLUTTER) in a randomized order with a one-week washout interval between them. The main outcomes were pulmonary function variables and expectorated sputum dry weight. [Results] ELTGOL cleared $0.34 \mathrm{~g}$ more of secretions than FLUTTER (95\% CI 0.11 to 0.57 ). When comparing the physiological effects of ELTGOL and FLUTTER, the first was superior in improving airway resistance $\left(-0.51 \mathrm{cmH}_{2} \mathrm{O} / \mathrm{L} / \mathrm{s} ; 95 \% \mathrm{CI}-0.88\right.$ to -0.14$)$ and airway conductance $\left(0.016 \mathrm{~L} / \mathrm{s} / \mathrm{cmH}_{2} \mathrm{O} ; 95 \%\right.$ CI 0.008 to 0.023$)$. [Conclusion] ELTGOL promoted higher secretion removal and improvement in airway resistance and conductance than the Flutter valve. These techniques were equivalent in reducing the pulmonary hyperinflation and air trapping in cystic fibrosis patients. Key words: Chest physiotherapy, Cystic fibrosis, ELTGOL
\end{abstract}

(This article was submitted Oct. 15, 2013, and was accepted Jan. 7, 2014)

\section{INTRODUCTION}

A few years ago, cystic fibrosis was considered a childhood disease, but life expectancy has increased in recent years due to medical advances and greater understanding of its pathophysiology, bringing the average age to 36.9 years old $^{1}$. In this context, chest physical therapy (CPT) has been playing an important role, aiding mucociliary clearance, which directly influences the survival and prognosis of these patients ${ }^{2,3)}$.

In the last few years, a number of CPT techniques have been proposed in order to reduce the frequency of recurrent pulmonary infections that progressively affect lung function $^{4}$, but many of these procedures require daily professional assistance, resulting in poor adherence to treatment. For this reason, techniques that allow independent treatment were developed and have been studied, such as autogenic drainage, active cycle of breathing, oral oscillatory

*Corresponding author. Fernando Silva Guimarães (E-mail: fguimaraes_pg@yahoo.com.br)

(C2014 The Society of Physical Therapy Science. Published by IPEC Inc. This is an open-access article distributed under the terms of the Creative Commons Attribution Non-Commercial No Derivatives (by-ncnd) License $<$ http://creativecommons.org/licenses/by-nc-nd/3.0/>. devices, high-frequency chest oscillation, positive expiratory pressure, and intrapulmonary percussive ventilation ${ }^{5)}$. Flutter valve ${ }^{\circledR}$ (Varioraw SARL, Scandipharm Inc, Birmingham, AL, USA), which combines positive expiratory pressure with high-frequency oscillations within airways, is a well-recognized and widely used device for the treatment of patients with cystic fibrosis ${ }^{6}$. In the last few years, ELTGOL (L'Expiration Lente Totale Glotte Ouverte en décubitus Latéral ${ }^{7}$ ) has emerged as an inexpensive and easy to perform therapeutic option. During ELTGOL, the patient lies laterally, with the affected lung in the dependent position, while performing a series of slow expirations with the glottis open. According to its original description, this technique is indicated for hypersecretive, cooperative patients, and those in which the forced maneuvers pose a higher risk of causing harmful airway collapses ${ }^{8}$. Therefore, as there are very few studies about the physiological and clinical effects of ELTGOL, the aim of this study was to compare the acute effects of ELTGOL and the Flutter valve in stable adult patients with cystic fibrosis.

\section{SUBJECTS AND METHODS}

This was a randomized, crossover study with a convenience sample of cystic fibrosis outpatients. The patients 
underwent two protocols (Flutter Valve and ELTGOL interventions), in a randomized order with a one-week washout interval between them. After the washout period and prior to the second intervention, the patients were reexamined by a physician to ensure that they remained stable. Pulmonary function tests were performed at the Pulmonary Function Laboratory (University of Rio de Janeiro), and the interventions were conducted by a cardiopulmonary physical therapist, always at the same time of the day, with the sessions scheduled between 9:00 and 12:00 AM. The allocation sequence was computer generated using one random block with a block size of fourteen. The protocol to be applied was revealed to the investigator only at the onset of each experimental sequence, and the participants were oriented to maintain their regular treatments during the period of the study.

We included individuals with clinical and laboratory (sweat test and/or deoxyribonucleic acid - DNA mutation analysis) diagnoses of CF from the Pneumology Service of Pedro Ernesto University Hospital (State University of Rio de Janeiro). Patients under any physiotherapeutic treatment and those with acute chest pain, recent history of hemoptysis, pneumothorax at least one year before the study, respiratory infection in the four weeks preceding the study, or a confirmed diagnosis of asthma were not included. According to the Helsinki Declaration, our Institutional Ethics Committee approved the study, and all subjects signed an informed consent form.

Sample size was estimated using the SigmaStat 3.1 software (SYSTAT Software Inc., Point Richmond, CA, USA), considering a power of $80 \%$ and $\alpha=5 \%$. According to the data from Konstan et $\mathrm{al}^{9)}, 8$ subjects were required for the study in order to detect a $74 \%$ difference and a $64 \%$ standard deviation in the secretion production (main outcome).

Two days before the testing protocols, each subject visited the laboratory for an introductory session to become familiar with the equipment and the procedures. Both interventions were preceded by the inhalation of two puffs of $100 \mathrm{mcg}$ of salbutamol, followed by a series of five minutes of coughing. The Flutter intervention (FLUTTER) was performed with the patients comfortably seated and breathing through the device for 15 minutes, starting off from total pulmonary capacity ${ }^{9}$. The device position (angle) was determined by the patient (within a limit of $30^{\circ}$ ) according to his/her adaptation and perception of the effectiveness of sputum clearance ${ }^{10)}$. In the ELTGOL intervention (ELTGOL), the subjects were in the side-lying position and performed slow exhalations through a mouthpiece, from the functional residual capacity (FRC) to the residual volume (RV). They performed three sets of ten repetitions with a two-minute interval between them, for both right and left lateral decubitus. During ELTGOL and FLUTTER, the patients were free to cough, and after both interventions, a 5-min session of coughing ensued.

The foremost outcome with respect to airway clearance was the expectorated sputum dry weight. Expectorated sputum was collected during the interventions and the subsequent coughing series using a sputum trap. The dry weight was determined after the samples had been in a drying oven
Table 1. Functional and demographic characteristics of the adult patients with cystic fibrosis $(n=14)$

\begin{tabular}{|c|c|}
\hline Age (yrs) & $26.7 \pm 5.4$ \\
\hline Gender $(\mathrm{M} / \mathrm{F})$ & $7 / 7$ \\
\hline Weight (kg) & $53.2 \pm 11.7$ \\
\hline Height (m) & $1.63 \pm 0.08$ \\
\hline BMI $\left(\mathrm{kg} / \mathrm{m}^{2}\right)$ & $19.7 \pm 2.7$ \\
\hline $\mathrm{FEV}_{1}(\%$ pred $)$ & $33.9 \pm 13.8$ \\
\hline FVC (\% pred) & $52.7 \pm 20.2$ \\
\hline $\mathrm{FEV}_{1} / \mathrm{FVC}(\%)$ & $54.9 \pm 6.4$ \\
\hline $\mathrm{FEF}_{25-75 \%}(\%$ pred $)$ & $12.1 \pm 6.2$ \\
\hline
\end{tabular}

at $65^{\circ} \mathrm{C}$ for 3 days to ensure complete dryness ${ }^{11)}$.

Forced spirometry, body plethysmography, and diffusion capacity were used to evaluate the short-term physiological effects of interventions (Collins Plus Pulmonary Function Testing Systems, Warren E. Collins, Inc., Braintree, MA, USA). These tests followed ATS/ERS standards ${ }^{12)}$, and predicted values were set according to the equations for the Brazilian population ${ }^{13,14)}$. The variables forced vital capacity (FVC), forced expiratory volume at the first second $\left(\mathrm{FEV}_{1}\right), \mathrm{FVC} / \mathrm{FEV}_{1}$, inspiratory capacity (IC), total lung capacity (TLC), residual volume (RV), airway resistance (Raw), and specific conductance (Gaw) were recorded after the first and second 5-min coughing series.

The data were analyzed using the software SigmaStat 3.1 software (SYSTAT Software Inc., Point Richmond, CA, USA). The between-interventions comparison was performed according to the pre- and post-intervention difference for each physiological variable (95\% CI). According to the data distribution, the paired t-test or Mann-Whitney rank sum test were used to compare pre- and post-intervention values within the same intervention. Differences were considered significant when $\mathrm{p}<0.05$.

\section{RESULTS}

The data from the fourteen patients were collected between February 2011 and December 2011. All enrolled subjects completed the study and tolerated well the experimental protocol. Table 1 shows the anthropometric and functional baseline characteristics of the participants. There were neither differences between pre-intervention values nor order effects. Mean (SD) scores, mean (SD) differences within interventions, and mean (SD) differences between interventions for sputum dry weight and the physiological measurements are shown in Table 2. ELTGOL cleared $0.34 \mathrm{~g}$ more of secretions than FLUTTER (95\% CI 0.11 to $0.57 ; p=0.024)$. In the within-intervention analysis, FLUTTER reduced TLC $(\mathrm{p}=0.024)$, FRC $(\mathrm{p}=0.035), \mathrm{RV}(\mathrm{p}=$ $0.027), \operatorname{RV} / \mathrm{TLC}(\mathrm{p}=0.024)$, Raw $(\mathrm{p}<0.001)$, and increased airways conductance (SGVa; $\mathrm{p}=0.001)$ and the peripheral 
Table 2. Sputum production and pulmonary function tests results in the FLUTTER and ELTGOL interventions

\begin{tabular}{|c|c|c|c|c|c|c|c|}
\hline & \multicolumn{2}{|c|}{ Pre-test } & \multicolumn{2}{|c|}{ Post-test } & \multicolumn{2}{|c|}{ Post-test minus pre-test } & \multirow{2}{*}{$\begin{array}{c}\begin{array}{c}\text { Difference between } \\
\text { interventions }\end{array} \\
\text { ELTGOL minus Flutter }\end{array}$} \\
\hline & Flutter & ELTGOL & Flutter & ELTGOL & Flutter & ELTGOL & \\
\hline \multicolumn{8}{|l|}{ Sputum Clearance } \\
\hline Sputum dry weight (g & & & $0.52(0.59)$ & $0.86(0.65)$ & & & $0.34(0.11$ to 0.57$)$ \\
\hline \multicolumn{8}{|l|}{ Spirometry } \\
\hline $\mathrm{FEV}_{1}(\mathrm{~L})$ & $1.17(0.53)$ & $1.09(0.51)$ & $1.17(0.51)$ & $1.11(0.50)$ & $0.01(0.06)$ & $0.02(0.14)$ & $0.01(-0.59$ to 0.08$)$ \\
\hline $\mathrm{FVC}(\mathrm{L})$ & $2.13(0.91)$ & $2.02(0.91)$ & $2.17(0.83)$ & $2.10(0.90)$ & $0.03(0.15)$ & $0.08(0.18)$ & 0.05 (-0.06 to 0.17$)$ \\
\hline $\mathrm{FEV}_{1} / \mathrm{FVC}(\%)$ & $54.9(6.4)$ & $54.9(7.1)$ & $54.0(8.07)$ & $53.29(7.82)$ & $-0.93(3.54)$ & $-1.64(5.24)$ & $-0.71(-4.08$ to 2.66$)$ \\
\hline $\mathrm{FEF}_{25-75}(\mathrm{~L})$ & $0.47(0.26)$ & $0.44(0.27)$ & $0.57(0.45)$ & $0.48(0.31)$ & $0.10(0.32)$ & $0.04(0.21)$ & $-0.06(-0.31$ to 0.19$)$ \\
\hline \multicolumn{8}{|l|}{ Plethysmography } \\
\hline $\mathrm{IC}(\mathrm{L})$ & $1.52(0.56)$ & $1.50(0.68)$ & $1.54(0.65)$ & $1.54(0.71)$ & $0.02(0.26)$ & $0.04(0.19)$ & $0.02(-0.17$ to 0.20$)$ \\
\hline $\mathrm{VC}(\mathrm{L})$ & $2.01(0.84)$ & $2.00(0.87)$ & $2.02(0.78)$ & $2.01(0.92)$ & $0.02(0.20)$ & $0.01(0.15)$ & $-0.1(-0.40$ to 0.33$)$ \\
\hline TLC (L) & $5.86(1.74)$ & $5.71(1.92)$ & $5.22(1.79)$ & $5.27(1.42)$ & $-0.64(0.93)$ & $-0.44(1.22)$ & $0.19(-0.30$ to 0.69$)$ \\
\hline FRC (L) & $4.33(1.36)$ & $4.21(1.62)$ & $3.70(1.47)$ & $3.74(1.10)$ & $-0.63(1.01)$ & $-0.48(1.22)$ & $0.15(-0.41$ to 0.72$)$ \\
\hline $\mathrm{RV}(\mathrm{L})$ & $3.84(1.29)$ & $3.71(1.73)$ & $3.21(1.36)$ & $3.26(1.05)$ & $-0.63(0.95)$ & $-0.45(1.20)$ & $0.18(-0.37$ to 0.73$)$ \\
\hline RV/TLC (\%) & $65.21(9.05)$ & $64.43(9.75)$ & $60.43(9.42)$ & $61.79(12.15)$ & $-4.79(7.04)$ & $-2.64(6.32)$ & $2.15(-1.78$ to 6.07$)$ \\
\hline $\operatorname{Raw}\left(\mathrm{cmH}_{2} \mathrm{O} / \mathrm{L} / \mathrm{s}\right)$ & $4.35(1.06)$ & $4.58(1.22)$ & $3.49(1.05)$ & $3.21(1.14)$ & $-0.86(0.65)$ & $-1.37(0.92)$ & $-0.51(-0.88$ to -0.14$)$ \\
\hline $\mathrm{SGVa}\left(\mathrm{L} / \mathrm{s} / \mathrm{cmH}_{2} \mathrm{O}\right)$ & $0.053(0.02)$ & $0.053(0.02)$ & $0.062(0.02)$ & $0.078(0.025)$ & $0.009(0.008)$ & $0.025(0.016)$ & $0.016(0.008$ to 0.023$)$ \\
\hline
\end{tabular}

Values are means (SD or $\mathrm{CI} 95 \%$ ). $\mathrm{FEV}_{1}=$ forced expiratory volume in 1 second; $\mathrm{FVC}=$ forced vital capacity; $\mathrm{FEF}_{25-75}=$ forced expiratory flow between 25 and $75 \%$ of the FVC; IC = inspiratory capacity; VC = vital capacity; TLC = total lung capacity; FRC = functional residual capacity; $\mathrm{RV}=$ residual volume; Raw = airway resistance; $\mathrm{SGVa}=$ airway conductance

arterial oxygenation $\left(\mathrm{SpO}_{2} ; \mathrm{p}=0.017\right)$. In ELTGOL, there was a reduction in Raw $(\mathrm{p}<0.001)$ and improvement in SGVa $(\mathrm{p}<0.001)$ and $\mathrm{SpO}_{2}(\mathrm{p}=0.034)$. When comparing the physiological effects of ELTGOL and FLUTTER, the former was superior in improving Raw $\left(-0.51 \mathrm{cmH}_{2} \mathrm{O} / \mathrm{L} / \mathrm{s}\right.$; $95 \% \mathrm{CI}-0.88$ to -0.14$)$ and SGVa $\left(0.016 \mathrm{~L} / \mathrm{s} / \mathrm{cmH}_{2} \mathrm{O} ; 95 \%\right.$ CI 0.008 to $0.023 ; \mathrm{p}=0.003$ ).

\section{DISCUSSION}

In this study, sputum production and the physiological consequences of two airway clearance techniques in adult cystic fibrosis patients were evaluated. We opted to compare ELTGOL with the Flutter valve because the latter is a well-established and widely used technique for the treatment of cystic fibrosis patients ${ }^{6}$. Both techniques resulted in physiological benefits, but ELTGOL promoted higher secretion removal and improvement in airway resistance and conductance than the Flutter valve. Although only the Flutter valve reduced pulmonary hyperinflation, a clinically relevant difference between the two evaluated techniques was not found for CPT, RV, and RV/CPT in this study, as shown by the confidence interval analysis.

Although airway clearance techniques are widely used, their physiological mechanisms and consequences are still poor understood. Airway clearance techniques are intended to remove pulmonary secretions from the periphery to more central airways, which can take several minutes after the end of their application. In our study, because we evaluated only the immediate effects of two chest physiotherapy techniques, it is likely that a significant amount of mucus was still in intermediate airways at the second pulmonary func- tion evaluation. The low sensitivity of forced spirometry to detect changes in the lung periphery and the presence of secretions in the intermediate and central airways after the interventions may explain the absence of significant differences in spirometric variables observed in our study ${ }^{15}$. Conversely, by means of impulse oscillometry, Scheidt et al. $(2010)^{16)}$ found a reduction in peripheral airway resistance and consequently in total resistance of the respiratory system after a single session with Flutter valve in hypersecretive patients with bronchiectasis. Similarly, but using body plethysmography, we found an improvement in Raw and SGVa after both ELTGOL and FLUTTER in patients with cystic fibrosis. When comparing these techniques, ELTGOL has proven superiority in improving the overall airway permeability (Raw and SGVa), but in the withinintervention analysis, only FLUTTER reduced pulmonary hyperinflation and air trapping. Despite this outcome, confidence interval analysis showed no differences when comparing TLC, RV, RV/TLC, and FRC between the two interventions. As, in theory, the airway impedance influences these static volumes, it is likely that a larger sample size would enable us to observe significant differences also in the within-intervention analysis for ELTGOL, corroborating the other clinical (sputum production) and physiological (airway resistance and conductance) findings.

Because conventional physiotherapy, i.e., postural drainage associated with chest percussion and/or vibration, cannot be carried out without a therapist, novel airway clearance techniques have been proposed with the aim of improving cystic fibrosis patients' adherence to treatment. The Flutter valve is easy to use and has well-proven clinical benefits ${ }^{17}$, making this oscillatory device a common choice for 
the treatment of cystic fibrosis patients. In our study, ELTGOL was equivalent to the Flutter valve in the reduction of airway resistance and pulmonary hyperinflation, showing superiority for secretion removal. The underlying mechanism of ELTGOL uses airways compression to improve airliquid interaction in the peripheral airways, thus promoting pulmonary secretion displacement. This principle also supports the use of autogenic drainage, in which the patient has to breathe at different pulmonary volumes to "unstick," "collect," and "evacuate" the secretions from the peripheral airways ${ }^{18)}$. Like Flutter valve, autogenic drainage has proven efficacy for patients with cystic fibrosis, but ELTGOL is inexpensive and easier to perform. These advantages have raised interest among therapists and researchers in the last few years. Therefore, ELTGOL has been shown to have positive effects in chronic obstructive pulmonary disease $^{19)}$ and chronic bronchitis ${ }^{20)}$ exacerbations and in stable patients with bronchiectasis ${ }^{21)}$ and chronic bronchitis $^{22}$. Among these studies the only study on the long-term impact of ELTGOL did not show any proven efficacy in reducing hospitalization or the number of exacerbations ${ }^{19)}$.

The main limitations of the present study are the small sample size and the lack of evaluation of the long-term effects of the interventions. Nevertheless, because the literature lacks information on the impact of ELTGOL in adult cystic fibrosis patients, in this first study, we evaluated only the short-term effects of the technique, comparing its results with a well-established procedure. Therefore, our results are not enough to recommend ELTGOL as a routine procedure in the treatment of $\mathrm{CF}$ patients but point out that is worthwhile to perform further research on this technique using long-term treatment designs and clinically relevant outcomes, such as quality of life and incidence of pulmonary exacerbations.

In conclusion, ELTGOL promoted higher secretion removal and improvement in airway resistance and conductance than the Flutter valve. These techniques were equivalent in reducing pulmonary hyperinflation and air trapping in adult cystic fibrosis patients.

\section{REFERENCES}

1) Ashlock MA, Olson ER: Therapeutics development for cystic fibrosis: a successful model for a multisystem genetic disease. Annu Rev Med, 2011, 62: 107-125. [Medline] [CrossRef]

2) Davis PB: Cystic fibrosis since 1938. Am J Respir Crit Care Med, 2006,
173: 475-482. [Medline] [CrossRef]

3) Bucks RS, Hawkins K, Skinner TC, et al.: Adherence to treatment in adolescents with cystic fibrosis: the role of illness perceptions and treatment beliefs. J Pediatr Psychol, 2009, 34: 893-902. [Medline] [CrossRef]

4) Pisi G, Chetta A: Airway clearance therapy in cystic fibrosis patients. Acta Biomed, 2009, 80: 102-106. [Medline]

5) Cohen-Cymberknoh M, Shoseyov D, Kerem E: Managing cystic fibrosis: strategies that increase life expectancy and improve quality of life. Am J Respir Crit Care Med, 2011, 183: 1463-1471. [Medline] [CrossRef]

6) Sontag MK, Quittner AL, Modi AC, et al. Investigators and Coordinators of the Airway Secretion Clearance Trial: Lessons learned from a randomized trial of airway secretion clearance techniques in cystic fibrosis. Pediatr Pulmonol, 2010, 45: 291-300. [Medline]

7) Postiaux G, Lahaye JM, Lens E, et al.: Le drainage postural en question. Kinesith Sci, 1985, 238: 13-43.

8) Postiaux G, Lens E: Orientations des choix thérapeutiques en kinésithérapie respiratoire. Rev Mains Libres, 1987, 11: 9-13.

9) Konstan MW, Stern RC, Doershuk CF: Efficacy of the Flutter device for airway mucus clearance in patients with cystic fibrosis. J Pediatr, 1994, 124: 689-693. [Medline] [CrossRef]

10) Fink JB, Mahlmeister MJ: High-frequency oscillation of the airway and chest wall. Respir Care, 2002, 47: 797-807. [Medline]

11) Placidi G, Cornacchia M, Polese G, et al.: Chest physiotherapy with positive airway pressure: a pilot study of short-term effects on sputum clearance in patients with cystic fibrosis and severe airway obstruction. Respir Care, 2006, 51: 1145-1153. [Medline]

12) American Thoracic Society: 1994 Update. Am J Respir Crit Care Med, 1995, 152: 1107-1136. [Medline] [CrossRef]

13) Pereira CA, Sato T, Rodrigues SC: New reference values for forced spirometry in white adults in Brazil. J Bras Pneumol, 2007, 33: 397-406. [Medline] [CrossRef]

14) Neder JA, Andreoni S, Castelo-Filho A, et al.: Reference values for lung function tests. I. Static volumes. Braz J Med Biol Res, 1999, 32: 703-717. [Medline]

15) van der Schans CP: Airway clearance: assessment of techniques. Paediatr Respir Rev, 2002, 3: 110-114. [Medline] [CrossRef]

16) Figueiredo PH, Zin WA, Guimarães FS: Flutter valve improves respiratory mechanics and sputum production in patients with bronchiectasis. Physiother Res Int, 2012, 17: 12-20. [Medline] [CrossRef]

17) Morrison L, Agnew J: Oscillating devices for airway clearance in people with cystic fibrosis. Cochrane Database Syst Rev, 2009, 21: CD006842. [Medline]

18) Schöni MH: Autogenic drainage: a modern approach to physiotherapy in cystic fibrosis. J R Soc Med, 1989, 82: 32-37. [Medline]

19) Kodric M, Garuti G, Colomban M, et al.: The effectiveness of a bronchial drainage technique (ELTGOL) in COPD exacerbations. Respirology, 2009, 14: 424-428. [Medline] [CrossRef]

20) Bellone A, Lascioli R, Raschi S, et al.: Chest physical therapy in patients with acute exacerbation of chronic bronchitis: effectiveness of three methods. Arch Phys Med Rehabil, 2000, 81: 558-560. [Medline] [CrossRef]

21) Guimarães FS, Moço VJ, Menezes SL, et al.: Effects of ELTGOL and Flutter VRP1 ${ }^{\circledR}$ on the dynamic and static pulmonary volumes and on the secretion clearance of patients with bronchiectasis. Rev Bras Fisioter, 2012, 16: 108-113. [Medline]

22) Martins JA, Dornelas de Andrade A, Britto RR, et al.: Effect of slow expiration with glottis opened in lateral posture (ELTGOL) on mucus clearance in stable patients with chronic bronchitis. Respir Care, 2012, 57: 420-426. [Medline] [CrossRef] 